\title{
The effect of the weld fusion zone shape on residual stress in submerged arc welding
}

\author{
A. Ishigami ${ }^{1}$ (i) - M. J. Roy ${ }^{2}$ J. N. Walsh ${ }^{3}$ - P. J. Withers ${ }^{3}$
}

Received: 19 July 2016 / Accepted: 26 September 2016 / Published online: 8 November 2016

(C) The Author(s) 2016. This article is published with open access at Springerlink.com

\begin{abstract}
A new multiple-electrode submerged arc welding technique has been developed that imparts improved fracture toughness properties in the heat affected zone, produces a narrower weld bead geometry, and can also be employed with lower heat inputs than conventional SAW. This study examines how the difference in the weld fusion zone profile affects residual stresses for weldments of API X70 steel made using the same consumable, heat input and restraint, varying only the shape of the weld fusion zone. The contour method and neutron diffraction have been employed to map and compare longitudinal and transverse residual stresses. Results show peak longitudinal stresses in the weld are within $50 \mathrm{MPa}$ for both, and this is believed to be because they have the same heat input and hence similar heat affected zone size. By contrast, the peak stress in the transverse direction is $120 \mathrm{MPa}$ lower for the new SAW
\end{abstract}

M. J. Roy

matthew.roy@manchester.ac.uk

A. Ishigami

a-ishigami@jfe-steel.co.jp

J. N. Walsh

joanna.walsh@manchester.ac.uk

P. J. Withers

p.j.withers@manchester.ac.uk

1 Joining, Strength Research Department, Steel Research Laboratory, JFE Steel Corporation, Yubinbango 260-0835 Chiba City, Chiba Prefecture, Chuo-ku, Kawasaki-cho, Japan

2 School of Mechanical, Aerospace and Civil Engineering, University of Manchester, Manchester, M13 9PL, UK

3 School of Materials, University of Manchester, Manchester, M13 9PL, UK technique. The reduction in transverse stress is attributed to a narrower fusion zone profile. The new SAW technique opens up the possibility of producing high quality narrower welds with lower heat input which could lead to significant reductions in residual stress.

Keywords Thick section welding · Residual stress . Neutron diffraction · Contour method · API X70 · Pipe . Oil \& gas

\section{Introduction}

Many industrial applications rely on thick section steel welds where the structural member requires high tensile strength, good low temperature toughness, high deformability, and corrosion resistance. Multiple electrode Submerged Arc Welding (SAW) is widely used to fabricate such steel structures, particularly in the oil and gas sector. It is well understood that residual stress develops in the welded region of steel materials due to volume misfit that accrues from differential expansion and contraction in differing parts of the welded joint, associated with the weld thermal cycle, as described in detailed review by Withers and Bhadeshia [1]. Since tensile longitudinal residual stress can negatively affect mechanical properties of welds such as fatigue strength, buckling strength, fracture toughness, stress corrosion cracking, creep damage, weld deformation, and weld metal cracking, it is desirable to reduce tensile residual stresses or to introduce compressive residual stress. There are a number of strategies to accomplish this, including static/transient thermal and mechanical tensioning and the use of low transformation temperature filler material.

Withers [2] has described and generalised strategies to leverage mitigation techniques. Mechanical and thermal 
post weld treatments such as post weld heat treatment, rolling, shot peening, carburized quenching, and induction quenching can all be used to re-engineer the near weld residual stress state, but these require additional processing steps. A reduction in residual stress has been obtained using low transformation temperature welding wire. With this technique, the chemical composition of the welding wire is optimized so that the martensitic transformation finishes just above room temperature so that the volume increases associated with the transformation can offset the thermal contraction strains. Moat et al. [3] describe this approach with specific filler metals for austenitic and ferritic welds.

A significant body of work has focused on optimising welding process parameters so as to reduce residual stress, as detailed in a recent review by Zondi [4]; essentially heat input (a function of welding voltage, current, and speed) is the most significant factor in determining the magnitude and distribution of residual stresses. An increase in heat input increases the level of tensile residual stress, increases the size of the HAZ and the tensile residual stress area, and increases the applied welding load which is directly related to welding distortion. This was shown by Colegrove et al. for a variety of fusion welding processes on DH36 steel [5]. This is because the heat input directly influences the size of the region that experiences the peak temperature during the welding thermal cycle, and the cooling rate obtained as shown by Francis et al. for high and low heat input welds performed on ferritic steel [6]. Regions experiencing higher temperatures incur greater contraction, and thus great misfit strain, hence, a larger heat input typically leads to a broader region of high tensile residual stress. Conversely, minimising the heat input diminishes the extent of the high tensile residual stress region. Additionally, a lower heat input causes the weld metal and surrounding HAZ to attain a higher cooling rate. This leads to a refinement of grain size in the HAZ, and a narrower HAZ width, resulting in improvement of HAZ toughness and suppressed HAZ softening. A decrease in local weld heat input with high speed welding may also save energy while retaining high productivity. However, low heat input welding is associated with the formation of defects such as lack of fusion in the centre of the weld and, given the stringent specifications on weld bead width and height, it is not possible to reduce the heat input and obtain a sufficient quality of weld with conventional multiple electrode methods. This aspect has been detailed by Bortsov et al. [7] who demonstrated a range of defects if high enough heat input is not reached for this type of welding.

Multiple electrode SAW using a smaller diameter lead welding electrode has been recently developed for the purpose of reducing weld heat input and obtaining improved mechanical properties of welds in heavy gauge steel plate. Kozuki et al. [8] described the process and benefits in detail, summarised in Fig. 1. In this SAW process, a smaller diameter lead welding wire as compared the trailing wires (Fig. 1a) enables an elevated arc concentration and an increase in resistant heating, resulting in an increased deposition rate for the same current as compared to conventional approaches with all wire diameters the same. This provides a with deeper penetration and a sharper deposition tip (Fig. 1b). The resulting changes to the weld cross-section in terms of distribution of microstructure and geometry provides elevated fracture toughness as measured by Charpy V-Notch (CVN) testing (Fig. 1c).

Ultimately, this new SAW process enables lower heat input welding compared to conventional SAW (CSAW), and consequently narrower fusion and HAZ, leading to the ability to obtain excellent toughness in the HAZ. While it is expected that the lower heat inputs will lead to overall lower residual stresses, it is unknown what the effect of the different weld bead geometry will have on the resulting residual stress distribution, although it might be anticipated that a narrower weld leads to lower residual stress through a reduction in shrinkage as better weld metal feeding is obtained. As a natural extension, the current work attempts to address whether the size/shape of the HAZ or fusion zone (FZ) is more important for determining the final residual stress state. In addition, due to the differences in welding procedure, and the importance of residual stress for structural integrity, comparative measurements of the residual stress state formed will lend confidence in adoption of this new procedure.

There are two principal categories of stress measurement in use; non-destructive and destructive. For confidence in the stress profiles measured, at least two different measurement techniques should be used. This is particularly the case where engineering assessments of critical infrastructure are concerned, according to Bate and Bouchard [9]. Neutron diffraction is recognized as being one of the most effective ways to measure bulk residual stress in heavy gauge steel plate non-destructively. Because neutrons interact weakly with materials, the technique is capable of deeper penetration than X-rays. However, since measurement time increases exponentially with increasing path length through the material, it is difficult to make measurements at many points deep within the sample. Moreover, the spatial resolution of neutron diffraction is restricted to millimeter dimensions. A further limitation of neutron diffraction is the need for appropriate arrangements to obtain strain-free lattice spacings $\left(\mathrm{d}_{0}\right)$ with an appropriate specimen; a poor choice of a $\mathrm{d}_{0}$ specimen can lead to an offset error in the magnitude of residual stress obtained. Best practice for dealing with this $\mathrm{d}_{0}$ issue is detailed by Withers et al. [10] and adhered to in the present work. As access to neutron diffraction facilities is somewhat limited, it is desirable to measure bulk residual stress in heavy gauge steel plate economically 
Fig. 1 a Schematic depiction of the new SAW method employing a smaller diameter lead wire versus the trailing wires. b Optical macrographs of conventional (above) and new (below) SAW welding with identical heat input in X70 steel. c Difference in fracture properties of conventional and new SAW taken from [8]
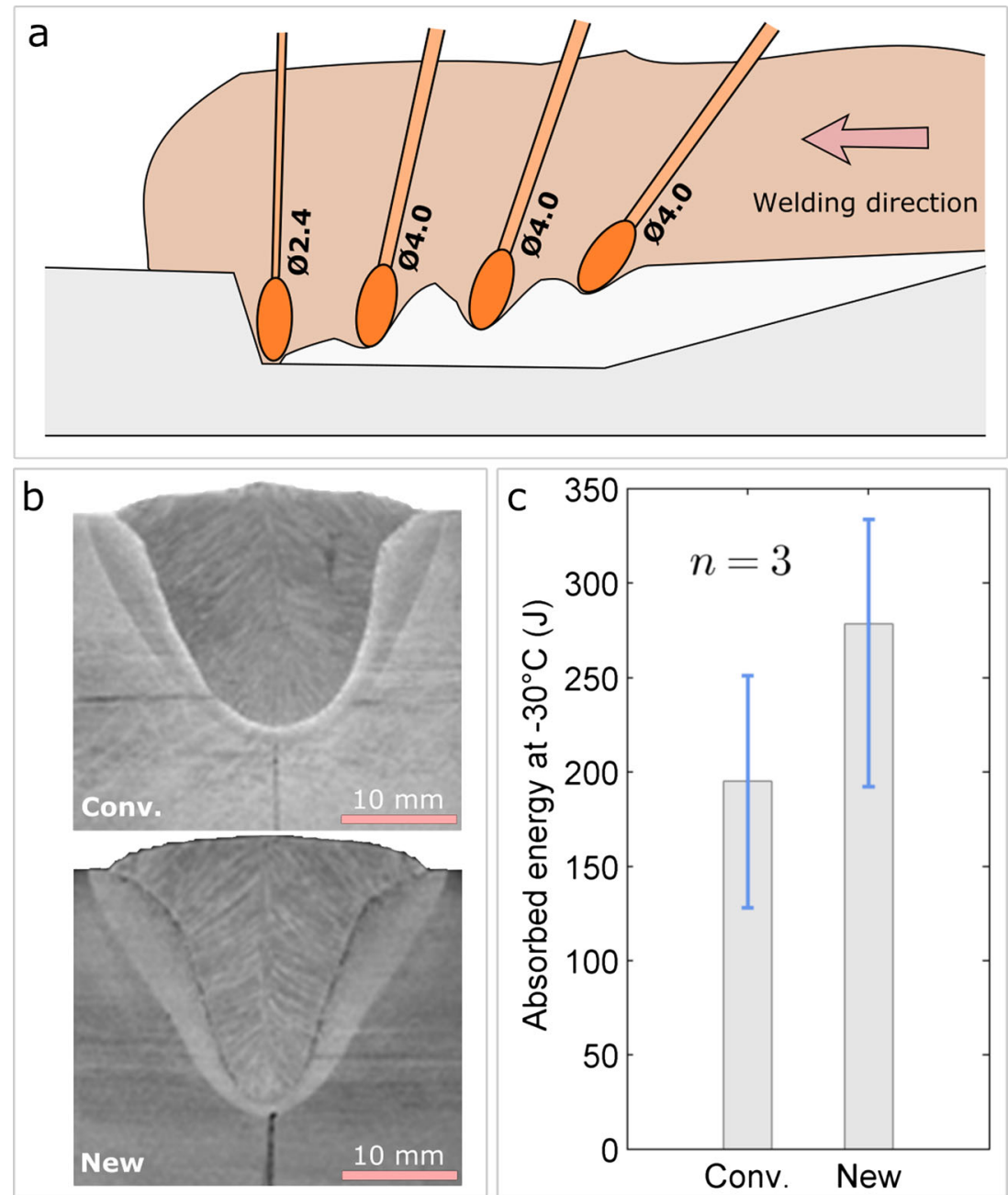

within the laboratory; something afforded by the contour method.

Prime [11] first proposed the contour method of determining residual stress, which enables bulk residual stress measurement for metallic materials. The contour method comprises three steps:

1. Experimentally cut the sample into two halves by wire electro discharge machining (EDM) while preventing any movement during cutting;

2. Measure the EDM cut surface to capture deformation due to stress relief; and

3. Analytically solve for the stress required to produce the deformation measured via Finite Element Analysis (FEA).

With the contour method, the depth of measurement from a given surface is only limited by the EDM and metrology equipment employed in the analysis, and a full 2D map of the stress normal to the cut plane is obtained. Due to the relative accessibility of the equipment required, the method is commercially very cost effective as compared to neutron diffraction. The principal disadvantages are that it is destructive, only one residual stress component is mapped and results are susceptible to cutting artefacts, particularly at the specimen edges.

Since the contour method gives residual stress normal to the EDM cut surface as described above, attempts have been made to measure multiple stress components by multiple cuts, such as by Pagliaro et al. [12], and later coupling the contour method with XRD [13]. However, most studies have been conducted on flat plate samples such as butt welded joints and bead on plate welds. To validate the contour results, most of these aforementioned studies have reported additional results measured by neutron and synchrotron $\mathrm{X}$ ray diffraction and particularly good agreement has been reported, such as by Thibault et al. [14] for stainless steel welded plates. There are examples in the literature where the contour method has been applied to assess more complicated welded pipe samples, most recently by Hosseinzadeh and Bouchard [15]. 
This work aims to quantify and compare the residual stress distributions in thick-walled X70 steel mockups representative of a tubular component welded with a conventional SAW (CSAW) technique, and a recently developed high speed new SAW (NSAW) technique. Welding restraint conditions reflecting those present in the manufacture of tubular components were simulated with the use of plate geometry and restraint to eliminate 'butterfly' distortion during all welding operations. In order to focus on the weld profile, effects similar levels of heat input were used for the two welds.

In this study, NSAW and CSAW welds were made using the same heat input, consumable, weld preparation, and restraint to separate the effect of the weld bead profile on the residual stress distribution from that of heat input, and to ensure that the new welding method did not incur a penalty in terms of residual stress generated. Thw use of a lower heat input while employing NSAW would be expected to be accompanied by further benefits in terms of reduced residual stress and improved mechanical properties. The current work is the first to focus on the effect of weld bead width at constant heat input to understand the effect of changing fusion zone boundaries on residual stresses for SAW. This study further aims to investigate whether the contour method can easily be extended to measure a 2D stress map of the transverse stresses as well as longitudinal, further enhancing its applicability for determining weld residual stresses. Finally, this work is the first to assess throughthickness residual stresses for API X70 steel weldments. This is data necessary to generate computational process models, validate them and permit further refinement.

\section{Experimental procedure}

\subsection{Sample preparation}

For the purpose of evaluating the effect of weld bead shape on the residual stress distribution in welded joint of heavy gauge thick plate, two double ' $V$ ' groove welded joints with the second ' $V$ ' weld having different weld bead shapes were prepared with the same weld heat input per unit length at JFE Steel Corporation's East Japan Works. The material used was API X70 steel plate rolled to a $26.8 \mathrm{~mm}$ thickness, $200 \mathrm{~mm}$ wide, and $1 \mathrm{~m}$ long. Run-off strips and restraints of the same thickness were affixed via GMAW welding. For one of the samples, CSAW was applied to both backing and finishing sides, and for the other sample, CSAW was applied to only to the backing side and NSAW was applied to the finishing side. Two sets of restraining plates, R1 and R2, were employed, with R1 to support the backing weld and removed via grinding prior to the finishing pass once the R2 series of restraints were applied. The R2 set of restraints were left on the component throughout the residual stress characterisation. Complete details regarding sample preparation, dimensions, and restraint procedure are shown in Fig. 2, with global manufacturing tolerances estimated at $\pm 4 \mathrm{~mm}$ for all dimensions depicted. The consumable type and offsets between electrodes were identical in all cases, with the difference between the new and conventional being that the lead electrode was 2.3 $\mathrm{mm}$ in diameter for new versus $4 \mathrm{~mm}$ for conventional (Fig. 1).

Welding conditions and groove depths are given in Table 1; the groove angle in all cases was $70^{\circ}$. The backing weld was carried out in an identical manner for both specimens, however, finish welding was carried out with identical groove shapes and identical heat input per unit length, with a slightly different welding power.

Figure 3 shows the geometry of the samples which were extracted from welded joints shown in Fig. 2. Two specimens were extracted from each of the CSAW and NSAW weldments. One was committed to contour method measurements, metallography, hardness testing, and $d_{0}$ samples for neutron diffraction, whilst the other was reserved for neutron diffraction (Fig. 3a).

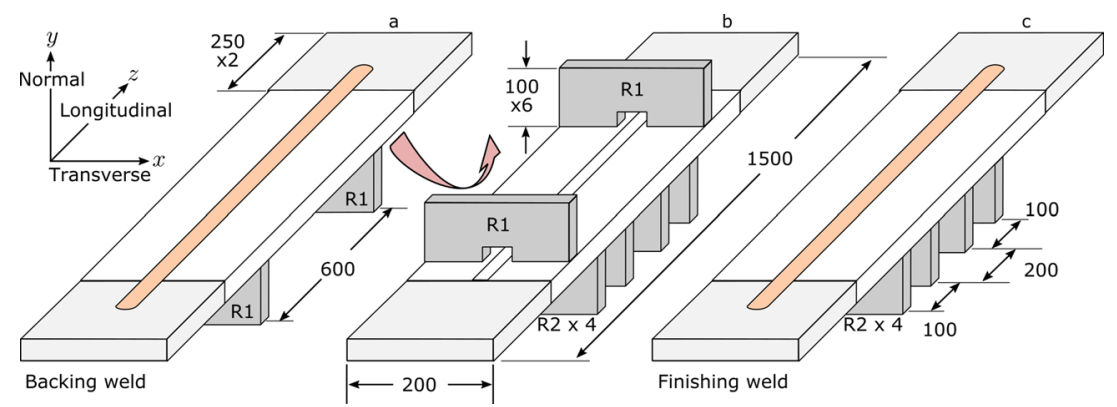

Fig. 2 Specimen welding sequence. Run-off strips, plate and two finishing-side restraints (R1) were tacked together and then the backing weld was performed (a). The specimen was then flipped and four finishing restraints (R2) were applied (b). The finishing-side restraints (R1) were removed and the finishing weld was performed (c). All dimensions in millimeters 
Table 1 Groove depth, fusion zone (FZ) width $7.5 \mathrm{~mm}$ from the plate surface, and welding conditions for each process and weld

\begin{tabular}{|c|c|c|c|c|c|c|}
\hline Technique & Weld & $\begin{array}{l}\text { Groove depth } \\
(\mathrm{mm})\end{array}$ & $\begin{array}{l}\text { FZ width } \\
(\mathrm{mm})\end{array}$ & $\begin{array}{l}\text { Welding speed } \\
(\mathrm{mm} / \mathrm{min})\end{array}$ & $\begin{array}{l}\text { Heat input } \\
(\mathrm{kJ} / \mathrm{mm})\end{array}$ & $\begin{array}{l}\text { Arc power } \\
(\mathrm{kW})\end{array}$ \\
\hline \multirow[t]{2}{*}{ Conventional } & Backing & 9.5 & 13.5 & 1600 & 4.44 & 188.40 \\
\hline & Finishing & 11.0 & 15.3 & 1470 & 5.97 & 146.27 \\
\hline \multirow[t]{2}{*}{ New } & Backing & 9.5 & 13.4 & 1600 & 4.44 & 188.40 \\
\hline & Finishing & 11.0 & 14.0 & 1370 & 5.97 & 136.32 \\
\hline
\end{tabular}

\subsection{Metallography and hardness testing}

To investigate the effect of the difference of weld bead profile between conventional and new conditions on microstructure and hardness, weld cross section samples were extracted and macrographs of the samples were taken to evaluate penetration depth, bead height and width of finishing welds on both joints at a single location. After inspection of the bead shape, the microstructure was investigated by optical microscopy and hardness mapping. Hardness mapping was carried out with a Struers DuraScan 80 automated Vickers hardness testing machine with $1 \mathrm{~kg}_{f}$ loading, with points distributed over an optimised mesh of spacing $\sim 1 \mathrm{~mm}$ produced using MATLAB ${ }^{1}$.

\subsection{Contour method}

Welded joint samples were cut along the plane normal to the welding direction with a wire-EDM (Agie-Charmilles FI440CCS CNC Wire EDM Machine) to measure the longitudinal residual stress distribution on the cut surface (Fig. 3b). EDM cutting was also performed at mid-length of the samples along the transverse direction of one of the halves, cutting from the weld and into the restraining plate (Fig. 3c). Specimens halves were rigidly clamped on either side of the cut to prevent rigid body movement and reduce cutting induced plasticity. After EDM cutting, distortion of the cut surface was measured using a laser scanner (NanoFocus $\mu$ Scan-CF4). After scanning of the cut surfaces, finite element analysis was performed using ABAQUS 6.13-1 $1^{2}$ and MATLAB to calculate the residual stress normal to the EDM cut surface from the deformation of the EDM cut surface. 3D models for FEA were created by extruding the EDM cut surface geometry along the longitudinal direction. Stress analysis was performed with Young's modulus $E=210 \mathrm{GPa}$ and Poisson's ratio of $v=0.30$ for both weld metal and base material.

After measurement of the longitudinal residual stress on cuts performed on the $x y$ plane, samples were cut in the $z y$

\footnotetext{
${ }^{1}$ MATLAB is a trademark of The MathWorks Inc., Natick, Massachusetts, United States

${ }^{2}$ ABAQUS is a trademark of Dassault Systémes, Surenes Cedex, France
}

plane with the wire traversing the weld first and then the restraint to acquire a transverse residual stress distribution (i.e., the wire moved in the $-y$ direction as shown in Fig. 3). The origin for the contour method stress measurements origins was taken as the weld centreline in $x$ and half the plate width in $y$ for both conventional and new joints.

Geometry, boundary conditions, and the characteristic mesh employed for the contour analysis is given in Fig. 4. The geometry for the FEA aspect of the longitudinal contour method measurement was generated by extruding the cross-section of the sample obtained via surface scanning by $100 \mathrm{~mm}$ in the $z$ direction. A similar approach was taken for the transverse analysis, where the restraint and plate outlines were extruded by $100 \mathrm{~mm}$. Macrographs were used to determine the weld bead and other details, and then the two components were joined by a section matching the local restraint plate thickness. The characteristic mesh used for longitudinal measurements contained approximately 81,000 elements and the transverse $\sim 103,000 \mathrm{C} 3 \mathrm{D} 10$ tetrahedral elements. Characteristic mesh edge lengths were $1.5 \mathrm{~mm}$, with a geometric distribution away from the cut face. One of the longitudinal analyses was repeated using C3D20 quadrilateral elements with the same edge length, and identical results were obtained.

Specific boundary conditions for the FEA were found from bivariate spline fitting of averaged point cloud measurements of the EDM cut surfaces. A cubic B-spline was employed with knot positions set every $4 \mathrm{~mm}$ in the weld region and $6 \mathrm{~mm}$ elsewhere to apply the displacement boundary conditions on the nodes corresponding to the cut face. Rigid body boundary conditions were applied to the bottom left and right-most nodes on each, preventing translation and rotation of the cut surface.

\subsection{Neutron diffraction}

Residual stress measurement was conducted using neutron diffraction with the intention of validating the contour method results. The neutron diffraction experiment was performed on the SALSA beamline [16] at the Institut Laue-Langevin, Grenoble, France. The samples for neutron diffraction measurement were the same as shown in Fig. 2 except that the holes on the restraining plates were opened 


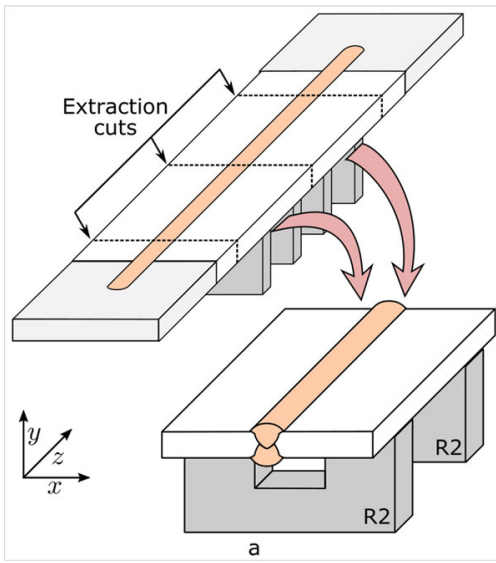

Fig. 3 Sample extraction and contour cutting arrangement. Specimens had two samples extracted via saw cutting (a); one for contour and $d_{0}$ measurement and the other for neutron diffraction. Longitudinal contour cuts were performed by clamping on either side of the cut face, as

from $60 \times 30 \mathrm{~mm}$ to $70 \times 100 \mathrm{~mm}$, retaining the same orientation about the centreline. This was to allow the neutron beam to avoid the restraint features which would otherwise attenuate the signal.

Measurement locations and dimensions employed for a $\mathrm{d}_{0}$ 'comb' specimen are given in Fig. 5, including specific locations identified as being representative of parent and weld metal along with the HAZ. Stress measurements were made at only one side of the weld center line in order to reduce measurement time. Equivalent positions were measured in the $\mathrm{d}_{0}$ specimen to provide accurate stress-free reference lattice spacings for all the measurement locations in both the longitudinal and transverse directions. Residual strains along the longitudinal, transverse, and throughthickness directions were measured using a gauge volume of $2 \mathrm{~mm} \times 2 \mathrm{~mm} \times 2 \mathrm{~mm}$ at all measurement points using a neutron beam having a characteristic wavelength of

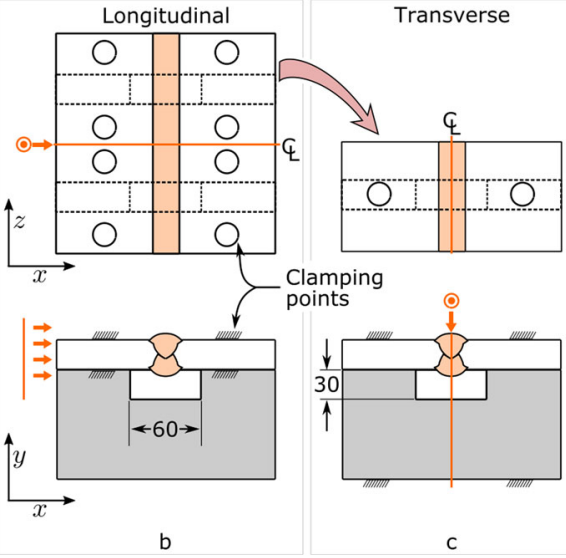

indicated (b). Once longitudinal cuts were completed, transverse contour cuts were performed by cutting first through the weld and then through the restraint while the arrangement was clamped both top and bottom (c). Extraction cuts are shown with black dashed lines, and EDM contour cuts in solid orange lines. All dimensions in millimeters

$1.642 \AA$ with a scattering angle $(2 \theta)$ of $\approx 90^{\circ}$. The (211) diffraction plane was used for the measurements and bulk elastic constants of $210 \mathrm{GPa}$ and Poisson's ratio of 0.30 were used for residual stress calculation because the (211) has a diffraction elastic constant close to that of the bulk. Neutron diffraction counting statistics were such that the error in diffraction peak fitting translated to $<1 \mathrm{MPa}$ in the calculated stress, additional sources of error from the $\mathrm{d}_{0} \mathrm{comb}$ weld profile were much higher.

Far from the weld, there should be no microstructure variations and, in the absence of retained stress, little to no variation in the measured $\mathrm{d}_{0}$. This was found not to be the case; the absolute variation in $\mathrm{d}_{0}$ at $40 \mathrm{~mm}$ from the weld centreline would give rise to 415 microstrains, and the variation from the mean 250 microstrains, which would lead to a change in stress of the order of 50-100 MPa. This suggested that the combs were not effectively stress relieved
Fig. 4 Characteristic mesh and boundary conditions for the contour method analyses on the conventionally welded specimen in both the a longitudinal and $\mathbf{b}$ transverse configurations. Distortion has been magnified $100 \times$. Note that only one node requires a zero-displacement boundary condition in the $x$ (longitudinal analysis) and $z$ (transverse analysis) direction to eliminate rigid body movement
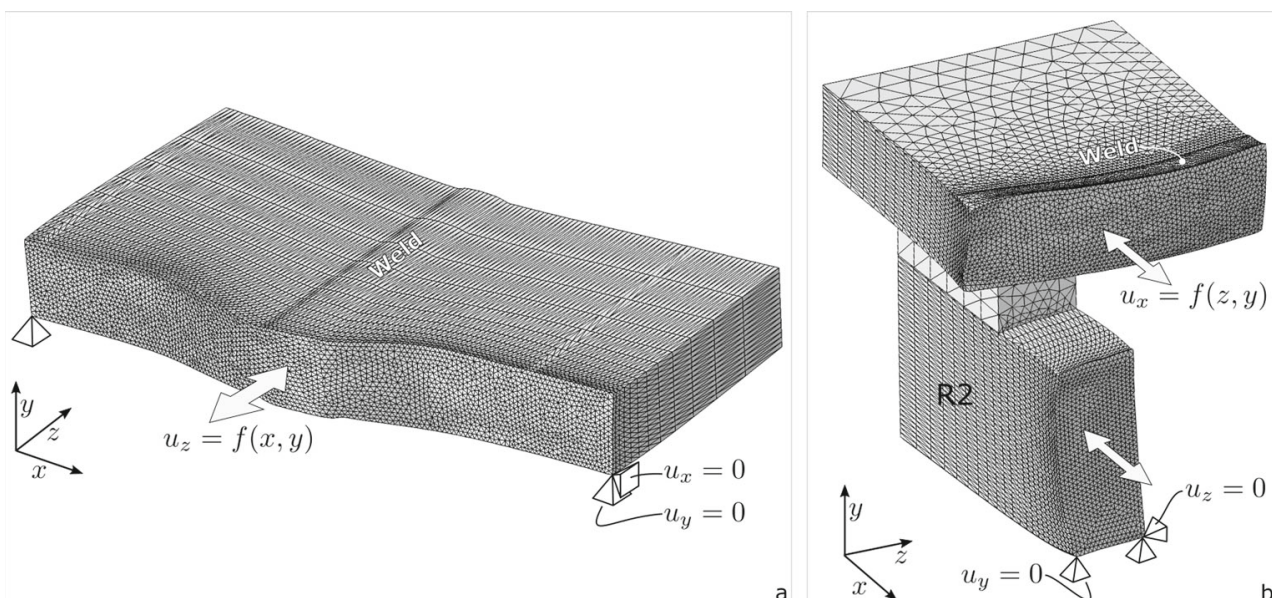
Fig. 5 Detail of neutron measurement arrangement, all dimensions in millimeters. The weld centreline was located 100 $\mathrm{mm}$ from a free edge in the $x$ direction for the purposes of creating a $\mathrm{d}_{0}$ specimen and locating measurement points. Highlighted points show positions used to find averaged $\mathrm{d}_{0}$ values for weld, HAZ and parent metal (left to right)

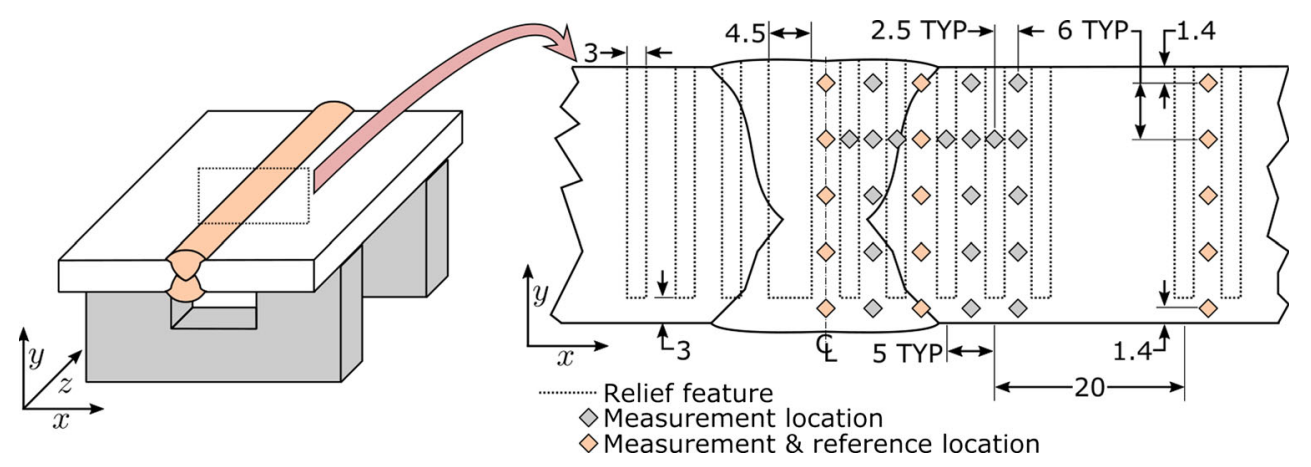

along their length and that there may have been a gauge problem in the measurement closest to the free tip of the comb. Thus, averaged transverse and longitudinal $\mathrm{d}_{0}$ values for weld metal, HAZ and parent material, at reference locations shown in Fig. 5 were used. A stress balance approach was also taken, as described by Withers et al. [10] where the normal stresses were assumed to be zero and the value of $\mathrm{d}_{0}$ was then back-calculated.
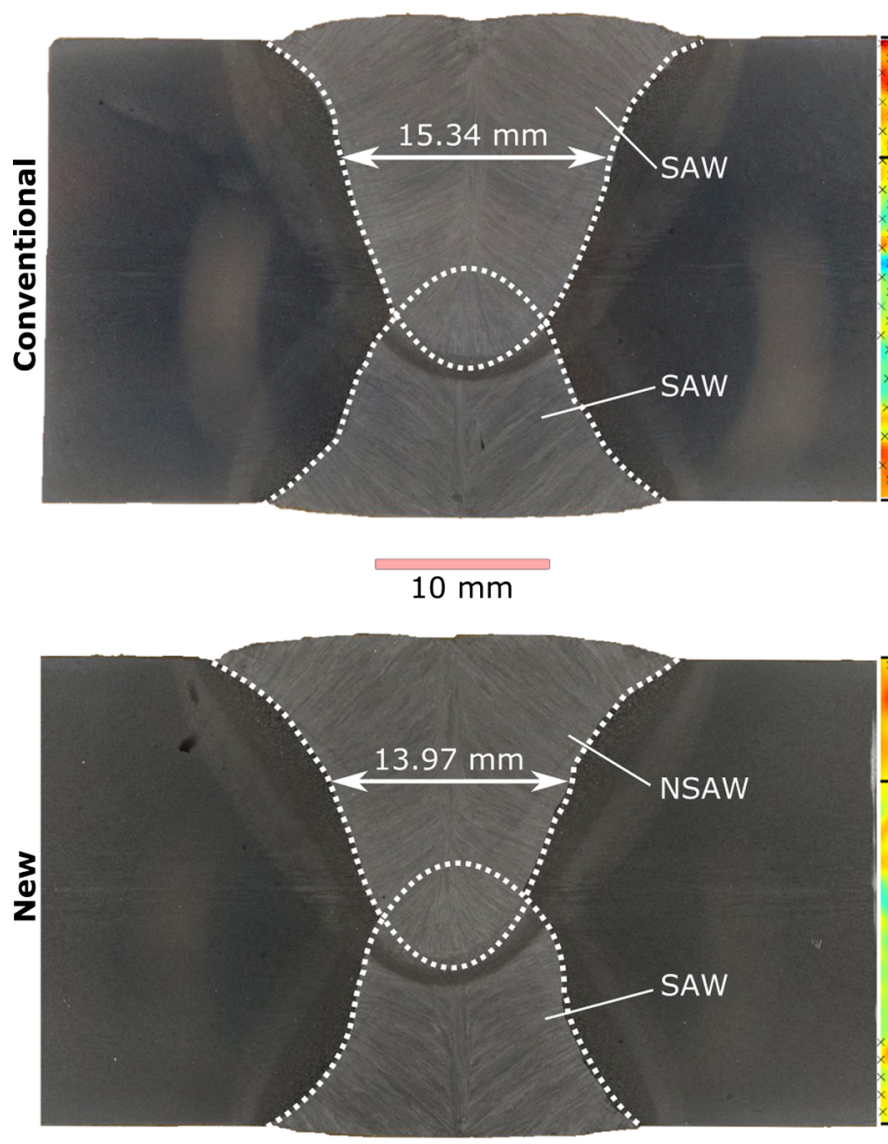

Fig. 6 Macrographs (left) and hardness maps (right) of characteristic cross sections for CSAW (top) and NSAW (bottom) welds. Dotted lines indicate the weld metal boundaries inferred from macrographs,

\section{Results and discussion}

\subsection{Microstructural characterisation}

As shown in the macrograph of the weld cross section of each joint (Fig. 6), a small weld crown was obtained for the finishing weld $(<2.5 \mathrm{~mm})$ for both techniques. Even though a common groove angle and heat input was employed in
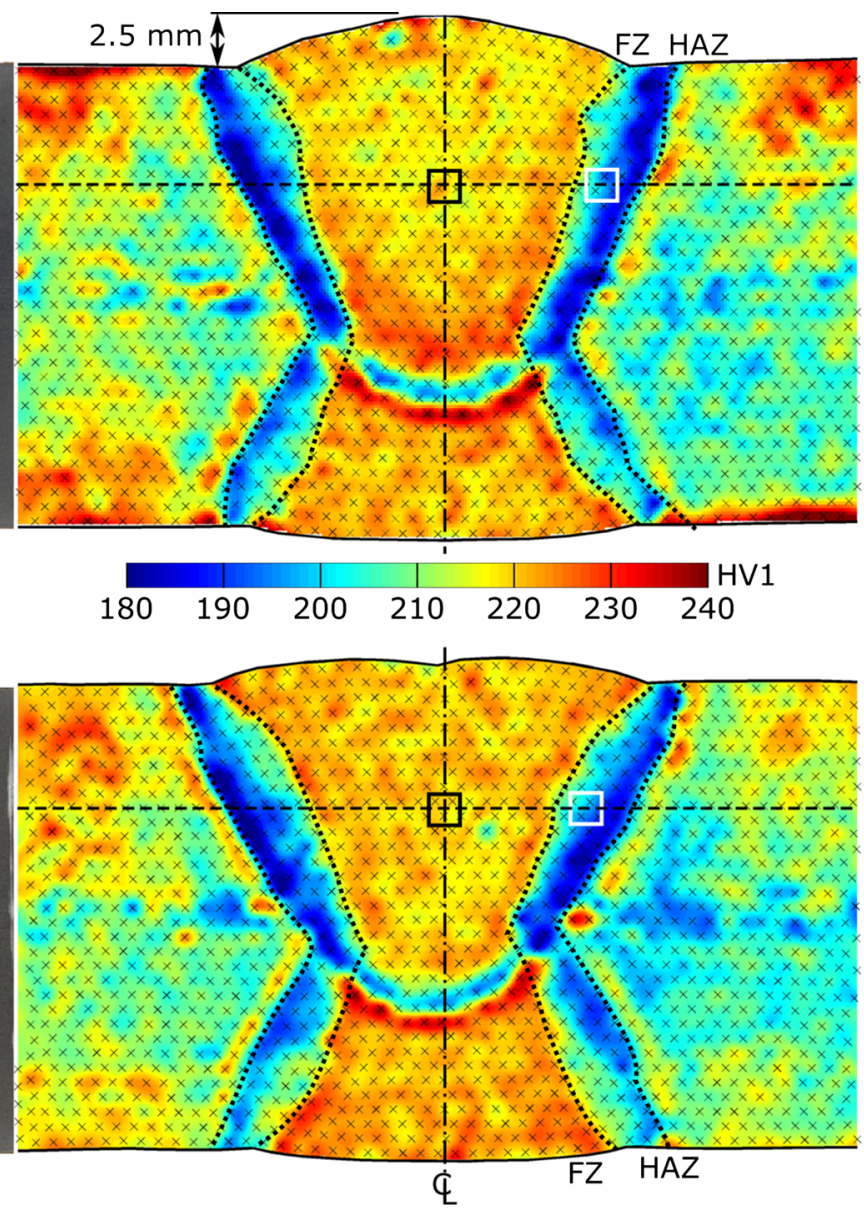

squares indicate location of micrographs in Fig. 7 and dashed lines correspond to locations in Fig. 11. Black crosses indicate hardness measurement point locations 
both NSAW and CSAW welds, the bead profile is different between the two. As compared to CSAW, at the top of the finishing weld, the NSAW had a slightly wider FZ and near-identical HAZ extent. Conversely, at the root of the weld, the NSAW featured a narrower FZ as well as a near-identical HAZ extent. The main difference between the HAZ widths of both finishing welds is observed at $7.5 \mathrm{~mm}$ below the surface, where is clear that the NSAW HAZ width is appreciably wider than the CSAW, even though the FZ is $\sim 1.3 \mathrm{~mm}$ narrower. The penetration depth of the NSAW finishing weld was slightly greater than that of CSAW by $\sim 1 \mathrm{~mm}$. It appears that the weld profile only changes slightly along the longitudinal direction in each weld; however, readily observable differences in fracture toughness properties between NSAW and CSAW welds produced with identical processing [8].

Figure 6 also shows a 2D map of hardness distribution across the weld and HAZ. It is evident that the hardness profile of the backing weld is almost identical in both cases. However, in the finishing weld, the HAZ is significantly different, corresponding to what is observed in the macrographs. While the width of the coarse grained HAZ (identified as regions between 200 and $220 \mathrm{HV} 1$ ) is approximately the same, the fine-grained HAZ (between 180-200 HV1) is significantly wider, even though the FZ (220-240 HV1) is narrower in the NSAW finishing weld.

It is believed that this slightly wider fine-grained HAZ is due to small differences in conductive heat transfer. The bulk of the heat flux is more narrowly biased towards the root in NSAW, as evidenced by the fusion zone. As a result, more heat must be transported from the midplane than CSAW, creating a slightly wider HAZ. It remains to be seen what the overall difference in performance is between the two approaches, as design engineers and operators need to decide whether a small region with a marginally decreased yield stength is tenable in light of improved fracture toughness and residual stress.

Figure 7 shows the microstructure of the weld metal and $\mathrm{HAZ}$ of the finishing weld for the two welded joints $\sim 7.5$ $\mathrm{mm}$ below the plate surface. The microstructure of both
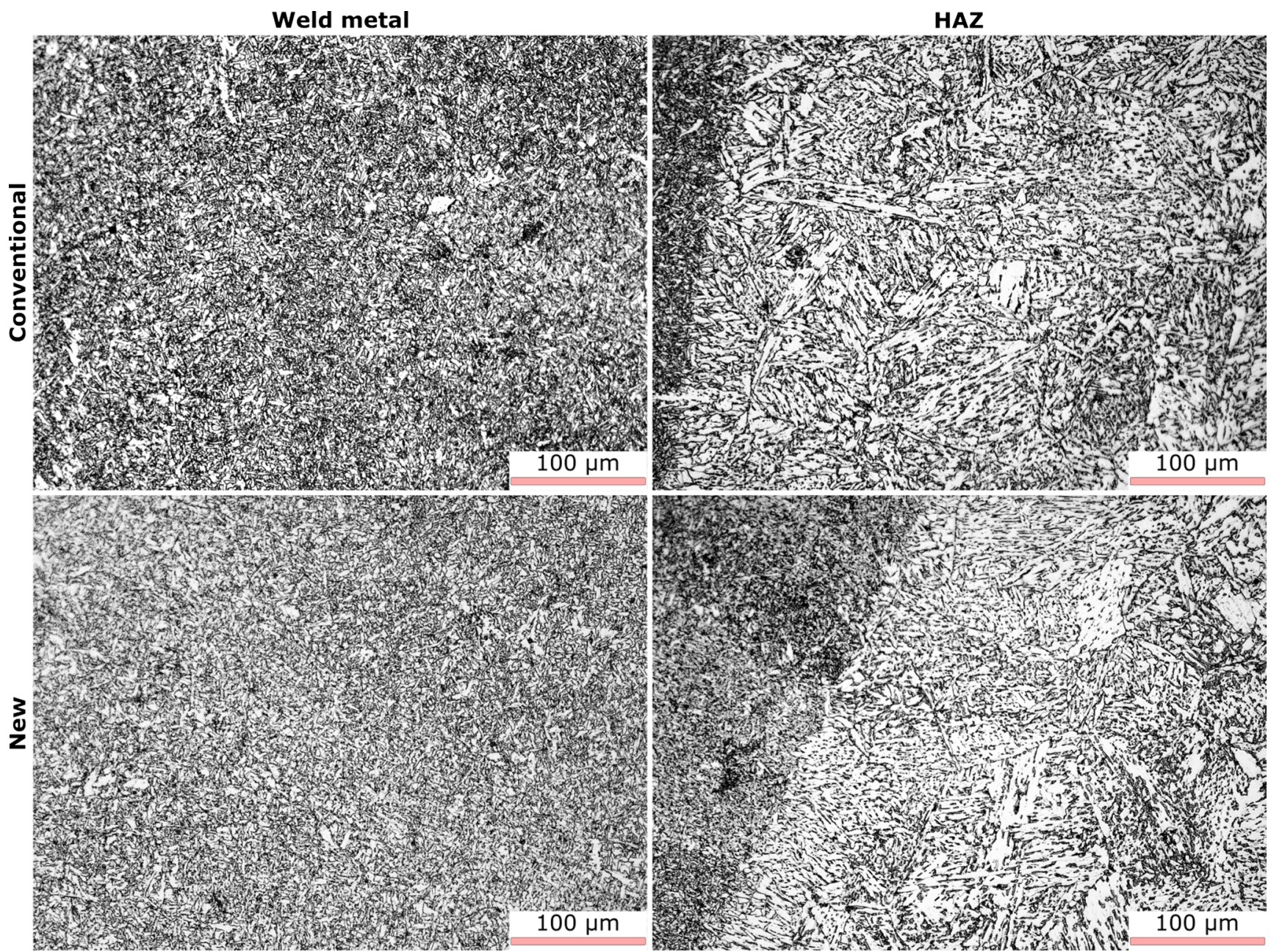

Fig. 7 Micrographs of weld metal (left) and HAZ (right) of the finishing weld for conventional and new (top \& bottom) NSAW welds. The locations from which the micrographs were taken are indicated in Fig. 6 


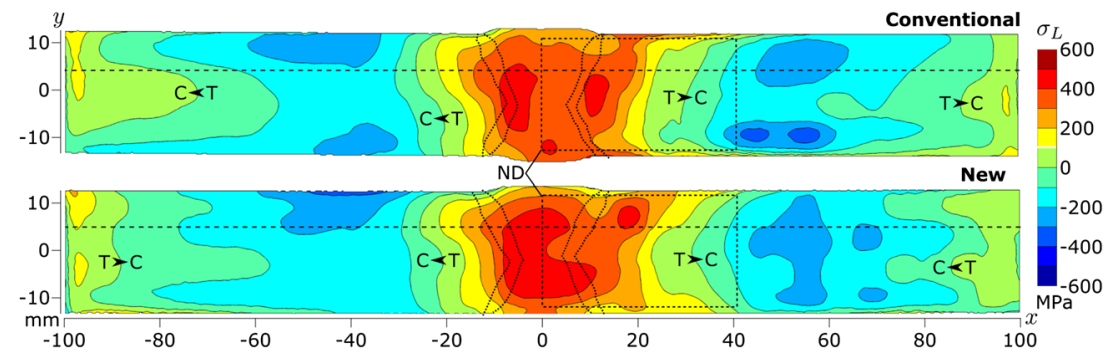

Fig. 8 Longitudinal residual stress obtained by contour method analysis. Fusion and HAZ boundaries from Fig. 6 are superimposed with dotted lines, the dashed box shows the region over which neutron

diffraction measurements were made as shown in Fig. 10. The line profiles in Figs. 6 and 11 were take along the dashed line at $y=5 \mathrm{~mm}$. The change from tensile (T) to compressive (C) stress has been annotated

welded joints is fine acicular ferrite in weld metal and bainite in the HAZ adjacent to the fusion boundary. These microstructures are typical of welds performed on API X70 class steels, when compared to those obtained by Li et al. [17] in the same grade of material with similar processing.

\subsection{Residual stress}

Figure 8 shows 2D maps of the longitudinal residual stress $\left(\sigma_{L}\right)$ distribution measured by the contour method across the weld cross section. While broadly similar, a slight difference in the overall distribution of longitudinal residual stress is evident between the two welded joints. The tensile region extends to $\sim 5 \mathrm{~mm}$ outside the HAZ in each weld, up to $40 \mathrm{~mm}$ from the weld centreline at the top and bottom of each plate and $20 \mathrm{~mm}$ from the weld centreline at the midpoint of each plate. The peak value of tensile longitudinal residual stress is very similar for CSAW and NSAW (460/470 MPa, respectively). Broadly speaking, the longitudinal residual stress state is identical between the two.

There is a slight bias in the distribution from one side to the other, with the transition from tensile to compressive occurring at $20 \mathrm{~mm}$ from the weld centreline on one side, and $30-40 \mathrm{~mm}$ on the other. This may be due to the slight misalignment between the backing and finishing welds or due to plasticity encountered during cutting. The 'die-away' length [18] in the out-of-plane direction, i.e., the location along $z$ where $\sigma_{L}=0$ was found to be approximately 40 $\mathrm{mm}$ for both welds. This implies that an adequate mesh length was employed, and the restraining plates were located sufficiently far enough away from the contour cut location.

The peak tensile stress value is close to the yield stress of API X70 class steel (485 MPa). In both welds, tensile stress in the weld and HAZ is balanced by compressive stress of $\sim 350 \mathrm{MPa}$ in the base plate $40-80 \mathrm{~mm}$ from the weld centreline. Such tensile stress is common in welds where high levels of contraction in the weld bead and HAZ are not offset by volume expansion due to phase transformation as seen in welds containing a high proportion of martensite [2]. A combination of high tensile residual stress and hardness is particularly deleterious for structural integrity.

Figure 9 show 2D maps of transverse residual stress at the weld centreline obtained by the contour method. Again, both welded joints show similar trends but in this orientation quite different peak values, i.e., a compressive residual stress developed $5 \mathrm{~mm}$ below the surface of the finishing weld accompanied by a tensile peak approximately one third of the way through for both backing and finishing welds. The finishing weld in the conventional SAW sample shows the highest tensile stress, 520 vs. $390 \mathrm{MPa}$ for the new SAW
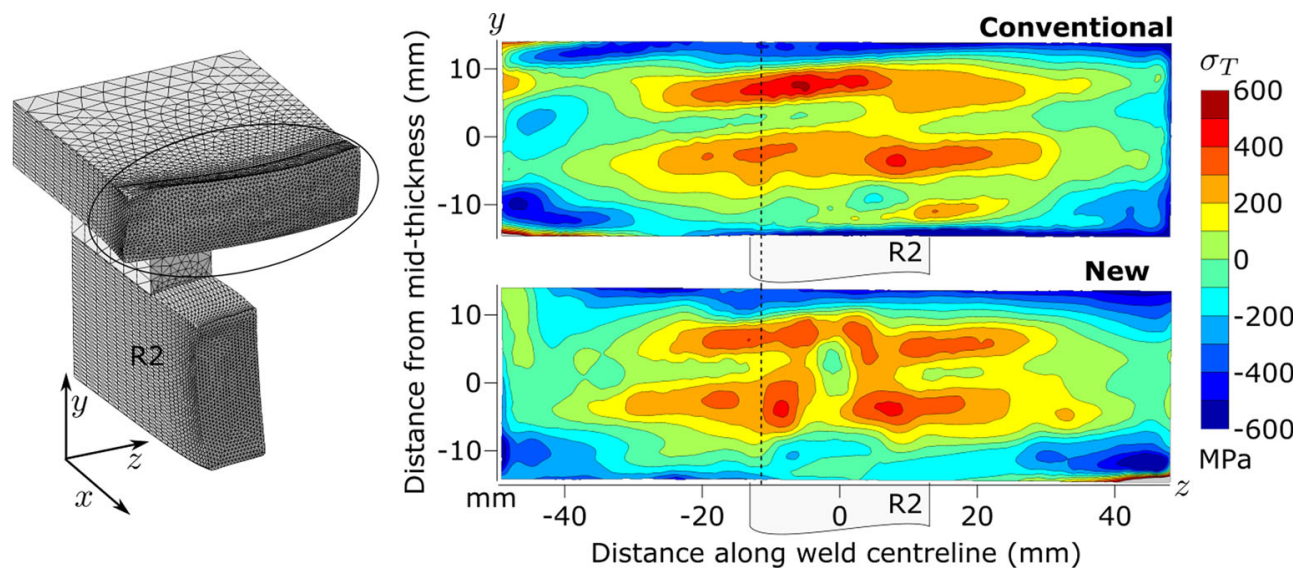

Fig. 9 Transverse residual stress along the weld centreline obtained by contour method analysis. The vertical dashed line denotes the line along which the contour stress data is plotted in Fig. 12 
weld. The cause for this peak to be higher than the reported yield is surmised to be due to a highly constrained hydrostatic residual stress state. However, peak stresses in the backing weld are similar in both cases, $\sim 420 \mathrm{MPa}$. The complex distribution of stress in each case is a function of varying transverse finishing and backing weld offset, the degree to which stresses were relieved by saw cutting and contour cutting performed on either side of the component, and the presence of the restraining plate.

Figure 10 shows the longitudinal and transverse residual stress across one side of the weld cross sections as measured by neutron diffraction, along with the longitudinal stresses determined by the contour method in equivalent regions. These neutron results were obtained by assuming that the normal stress values were zero. The longitudinal neutron measurements are broadly similar to the contour method but approximately 50-100 MPa higher, again showing that the longitudinal stresses are very similar between the two welds. The neutron diffraction results for the transverse stress show that the conventional weld has a peak tensile region approximately at the root of the finishing pass, with this region extending further away from the weld centreline than the new weld.
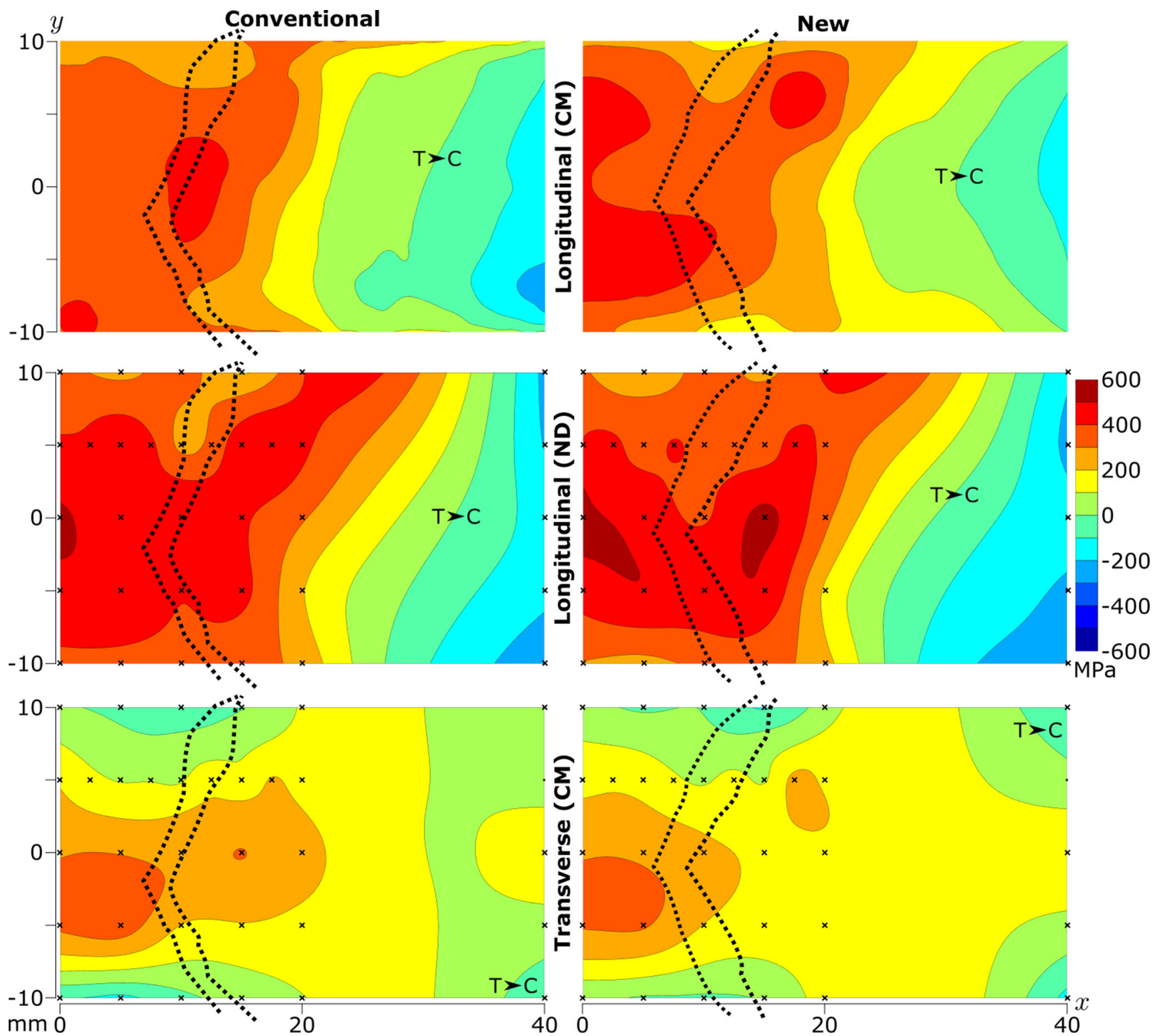

Fig. 10 Maps of residual stresses as seen on the $x y$ plane, plotted from the weld centreline $(\mathrm{x}=0)$. Longitudinal stress found from the contour method is compared to the same region/orientation obtained from neutron diffraction alongside fusion and HAZ boundaries. The same shown for transverse stresses found by neutron diffraction. Black

crosses indicate neutron diffraction measurement locations, and neutron diffraction results were calculated assuming zero normal stress. The change from tensile $(\mathrm{T})$ to compressive $(\mathrm{C})$ stress has been annotated 
Figure 11 compares the longitudinal residual stress between measurement methods with the position of the HAZ identified via hardness results taken approximately halfway through the finishing weld for each case. Although the trends of the stresses as determined by neutron and contour broadly agree, the magnitudes found by neutron in the region of the HAZ demonstrate some discrepancies. This is surmised to be due to both a strong influence of texture and slight variation in weld position/shape at the two locations selected. With the uncertainty in the neutron diffraction measurements arising from the variation in position specific $\mathrm{d}_{0}$, both techniques agree well. Since the peak stresses approach yield, it is also possible that some plasticity has occurred during contour cutting, which is known to shift and reduce the location and magnitude of the peak stress determined [19]. However, as the cutting parameters were the same between the two components, this demonstrates that there is little difference between the two welds, albeit the $\mathrm{HAZ}$ is larger in the new SAW case.

Figure 12 compares the stresses found in the transverse direction in a similar manner to Fig. 11. It can again be seen that there is a reasonable agreement in magnitudes between the contour results and neutron diffraction for the whole joint, and in trend for the backing weld only. While the neutron results do not show the double peak observed in the contour results, it is clearly evident that the measurement locations and density were not sufficient to capture the peak stress locations. Furthermore, the different $\mathrm{d}_{0}$ approaches highlight the effects of texture variation. The double peak observed is surmised to be due to the interaction of the backing and finishing weld. The finishing weld both induces new residual stress and redistributes the stress developed during the backing run to appear just above the finishing root. The second peak is due to the finishing pass and is clearly found smaller in the new SAW weld.

The main conclusions based on these collected observations are, firstly, that both neutron and contour measurements show the existence of high near yield level tensile residual stress in the longitudinal and transverse directions of CSAW and NSAW welds, the magnitude of which approaches the yield stress of the material. According to the neutron diffraction measurements, the CSAW and NSAW welding processes produce almost identical stress fields. The contour method also determined almost identical
Fig. 11 Longitudinal residual stress as measured by the contour method and neutron diffraction, as a function of distance from the weld centreline, at the weld mid-thickness. Error bars are the result of using direction-averaged, separated and spatially-averaged $\mathrm{d}_{0}$ values. Hardness along the same section is also shown to highlight the HAZ
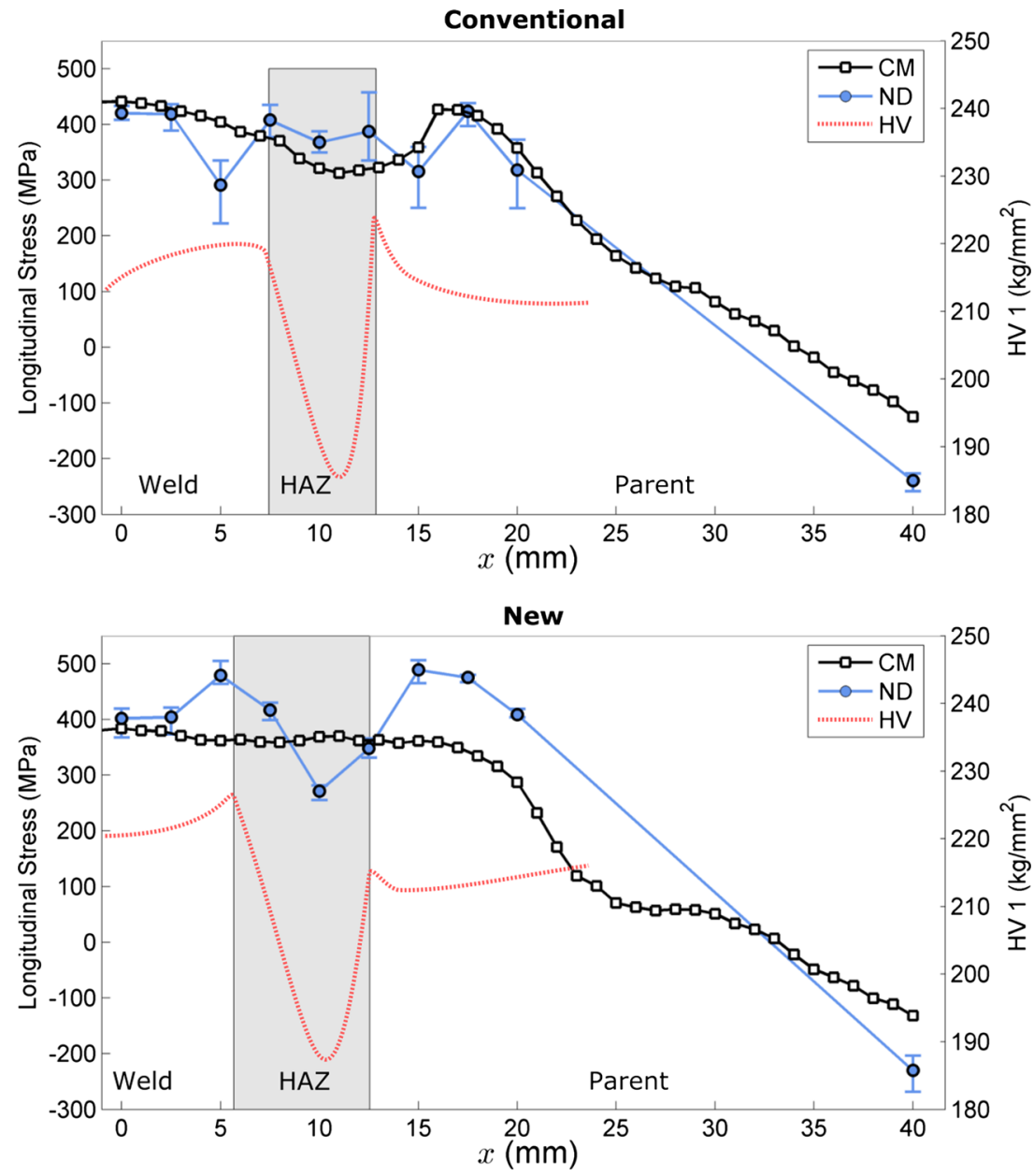
Fig. 12 Transverse residual stress as a function of the depth through the plate, measured via the contour method and neutron diffraction taken at the weld centreline $(x=0)$. Error bars are the result of using directionaveraged, separated and spatially-averaged $\mathrm{d}_{0}$ values. The base of the finishing weld is indicated by the first vertical dashed line, identified from hardness measurements. The relative contribution/influence of the two welding steps on each component through-thickness is inferred
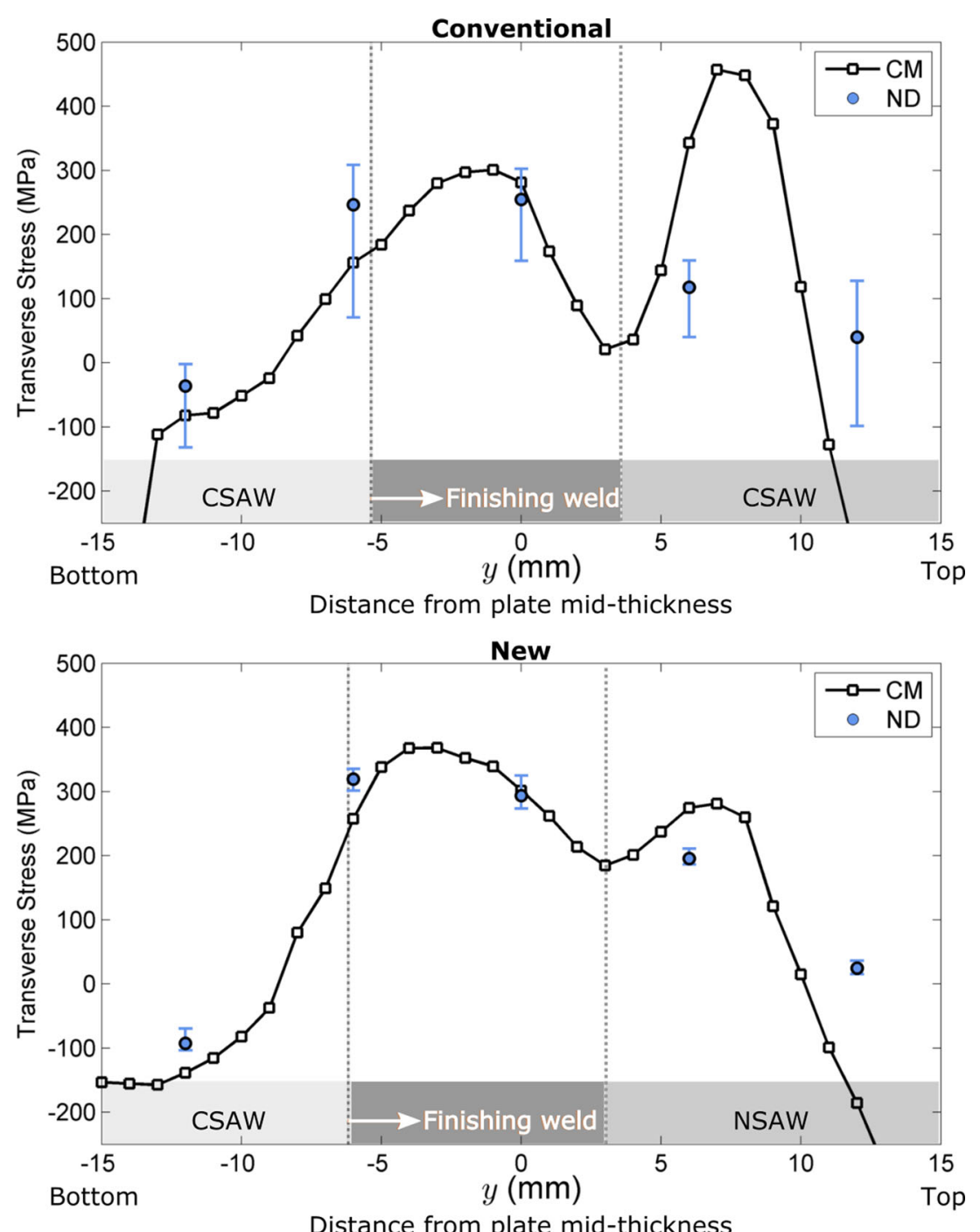

longitduinal stress distributions for CSAW and NSAW, but did show a noticable difference in the transverse stress distribution which was not evident in the neutron results due to limited spatial coverage. This highlights the advantage of the contour method over neutron diffraction; given the time and cost restrictions for neutron diffraction measurements it cannot be guaranteed that the location and magnitude of the peak stresses will be captured, whereas the 2D stress map generated by the contour method enables stress variations over a short $(<1 \mathrm{~mm})$ lengthscale to be resolved.

Secondly, given the inherent differences in fusion line profile, HAZ width, and even weld centreline, of a few $\mathrm{mm}$ are not significant in terms of distinguishing the CSAW and NSAW processes with the variability found with SAW welding. However, since the macrographs were taken at the plane of the stress measurements, it can be speculated that the difference in transverse stress measured at this location is due to the change in weld bead profile observed.

\section{Conclusion}

Two weld samples of API X70 steel were fabricated with identical consumables and restraint conditions representative of welded pipe. These were produced with similar welding heat inputs using a four electrode SAW process. Changing the diameter of the lead wire from a conventional $4 \mathrm{~mm}$ to a new $2.4 \mathrm{~mm}$ (CSAW vs. NSAW) produced a weld cross-section which had a narrower root and wider cap, and $\mathrm{a} \sim 1.3 \mathrm{~mm}$ wider HAZ overall.

The findings obtained are as follows:

- While the same groove shape and same weld heat input per unit length were applied, small differences between the two weld bead profiles were seen with a greater penetration and wider HAZ shape in the new SAW weld as compared to the conventional one. While the observed microstructure was essentially the same, the distribution of hardness in the HAZ for both welded joints were minor. 
- The contour method was applied to measurement of longitudinal and transverse residual stress in welded joints of heavy gauge steel plate and was compared with neutron diffraction. In this case, neutron diffraction measurements were seen to be at a disadvantage to contour method results due to the uncertainty of the $\mathrm{d}_{0}$ determination and the reduced coverage.

- The residual stress distribution of conventional and new SAW showed only very slight differences in the longitudinal direction, with the peak tensile stress approaching yield in both welds. This is thought to be due to the similar heat inputs employed.

- For the transverse direction, the stresses in the new SAW weld were found to be noticeably lower $(\sim 120 \mathrm{MPa})$, as identified by the contour method, but the peak tensile stress in the conventional weld was still close to yield.

- The results indicate that the differences in the residual stress distribution and magnitude for each type of weld were due to the FZ profile obtained and to a lesser extent, the HAZ produced.

The implications of our findings are as follows. The transverse stresses for constrained welds or the butterfly distortion for unconstrained welds appears to be effectively reduced by narrowing the weld bead, accomplished by more localised heat input. This of itself has little effect on the longitudinal stress but it is surmised that by combining a narrower weld bead width with lower heat input compared to the conventional SAW it would be possible to reduce both transverse and longitudinal residual stresses.

Acknowledgments The authors would like to thank JFE for both direct and in-direct support of this research. The authors would also like to thank the Institut Max von Laue-Paul Langevin for the allocation of beamtime at SALSA and gratefully acknowledge the help of Thilo Pirling for his assistance in performing the neutron diffraction experiments. A. Ishigami would like to thank Kenji Oi for his support of this research. M. J. Roy would like to thank Ian Winstanley for his assistance in performing the contour cuts. M. J. Roy acknowledges financial support from the EPSRC (EP/L01680X/1) through the Materials for Demanding Environments Centre for Doctoral Training.

Open Access This article is distributed under the terms of the Creative Commons Attribution 4.0 International License (http:// creativecommons.org/licenses/by/4.0/), which permits unrestricted use, distribution, and reproduction in any medium, provided you give appropriate credit to the original author(s) and the source, provide a link to the Creative Commons license, and indicate if changes were made.

\section{References}

1. Withers P, Bhadeshia H (2001) Residual stress. part 2 nature and origins. Mater Sci Tech Ser 17(4):366-375. doi:10.1179/026708301101510087

2. Withers P (2013) Strategies for the minimisation of residual stresses in welds. In: Debroy T, David SA, Bhadeshia HK (eds) ASM Proceedings of the International Conference: Trends in Welding Research, pp. 139-147
3. Moat RJ, Stone HJ, Shirzadi AA, Francis JA, Kundu S, Mark AF, Bhadeshia HKDH, Karlsson L, Withers PJ (2011) Design of weld fillers for mitigation of residual stresses in ferritic and austenitic steel welds. Sci Technol Weld Joi 16(3):279-284. doi:10.1179/1362171811Y.0000000003

4. Zondi M (2014) Factors that affect welding-induced residual stress and distortions in pressure vessel steels and their mitigation techniques: a review. J Press Vess-T ASME 136(4). doi:10.1115/1.4026564 https://energyresources.asmedigitalcollection.asme.org/data/ Journals/JPVTAS/929985/pvt_136_04_040801.pdf

5. Colegrove P, Ikeagu C, Thistlethwaite A, Williams S, Nagy T, Suder W, Steuwer A, Pirling T (2009) Welding process impact on residual stress and distortion. Sci Technol Weld Joi 14(8):717725. doi:10.1179/136217109X406938

6. Francis J, Turski M, Withers P (2009) Measured residual stress distributions for low and high heat input single weld beads deposited on to SA508 steel. Mater Sci Tech Ser 25(3):325-334. doi:10.1179/174328408X372074

7. Bortsov A, Shabalov I, Velichko A, Mentyukov K, Utkin I (2013) Features of multi-electrode submerged-arc welding in the production of high-strength thick-walled pipes. Metallurgist+ 57(34):310-319. doi:10.1007/s11015-013-9730-0

8. Kozuki S, Hayakawa N, Oi K (2015) Multiple-electrode submerged arc welding process with low heat input. JFE Technical Report 20:106-111. http://www.jfe-steel.co.jp/en/research/report/ 020/pdf/020-21.pdf

9. Bate S, Bouchard P (2011) The validation of weld residual stresses for use in structural integrity assessment. Appl Mech Mater 70:297302. doi:10.4028/www.scientific.net/AMM.70.297. https://www. scopus.com/inward/record.uri?eid=2-s2.0-80054816892\&amp; partnerID=40\&amp;md5=6f37db4ab15faa976c8f9c816872df47

10. Withers P, Preuss M, Steuwer A, Pang J (2007) Methods for obtaining the strain-free lattice parameter when using diffraction to determine residual stress. J Appl Crystallogr 40(5):891-904. doi:10.1107/S0021889807030269. http://scripts.iucr.org/cgi-bin/ paper?ks5141

11. Prime MB (2001) Cross-sectional mapping of residual stresses by measuring the surface contour after a cut. J Eng MaterT ASME 123(2):162-168. doi:10.1115/1.1345526. http:// materialstechnology.asmedigitalcollection.asme.org/article.aspx? articleid $=1426406$

12. Pagliaro P, Prime MB, Swenson H, Zuccarello B (2010) Measuring multiple residual-stress components using the contour method and multiple cuts. Exp Mech 50(2):187-194. doi:10.1007/s11340-009-9280-3

13. Pagliaro P, Prime M, Robinson J, Clausen B, Swenson H, Steinzig M, Zuccarello B (2011) Measuring inaccessible residual stresses using multiple methods and superposition. Exp Mech 51:11231134. doi:10.1007/s11340-010-9424-5

14. Thibault D, Bocher P, Thomas M, Gharghouri M, Côté M (2010) Residual stress characterization in low transformation temperature $13 \% \mathrm{Cr}-4 \% \mathrm{Ni}$ stainless steel weld by neutron diffraction and the contour method. Mat Sci Eng A 527(23):62056210. doi:10.1016/j.msea.2010.06.035. http://www.sciencedirect. com/science/article/pii/S0921509310006684

15. Hosseinzadeh F, Bouchard P (2013) Mapping multiple components of the residual stress tensor in a large P91 steel pipe girth weld using a single contour cut. Exp Mech 53(2):171-181. doi:10.1007/s11340-012-9627-z

16. Pirling T, Bruno G, Withers PJ (2006) Salsa a new instrument for strain imaging in engineering materials and components. Mat Sci Eng A 437(1):139-144. doi:10.1016/j.msea.2006.04.083. http:// www.sciencedirect.com/science/article/pii/S0921509306005053

17. Li C, Wang Y, Chen Y (2011) Influence of peak temperature during in-service welding of API X70 pipeline steels 
on microstructure and fracture energy of the reheated coarse grain heat-affected zones. J Mater Sci 46(19):6424-6431. doi:10.1007/s10853-011-5592-7

18. Foroogh Hosseinzadeh Jan Kowal PJB (2014) Towards good practice guidelines for the contour method of residual stress measurement. J Eng. doi:10.1049/joe.2014.0134
19. Dennis R, Bray D, Leggatt N, Turski M (2008) Assessment of the influence of plasticity and constraint on measured residual stresses using the contour method. ASME Pressure Vessels and Piping Conference:477-485. doi:10.1115/PVP2008-61490. http:// www.scopus.com/inward/record.url?eid=2-s2.0-78049351402\&; partnerID=40\&;md5=814d370c57981540b281f559d6502f60 